\title{
Fitzpatrick, Brian T. (2019). The Conservative Case For Class Actions. Chicago: The University Of Chicago Press. 271 pp.
}

Esta ha sido una obra polémica en su país de origen. Como bien es sabido, en Estados Unidos el régimen de acciones colectivas desde hace muchos años ha sido objeto de un intenso debate y crítica. En dicho contexto fallos de la Corte Suprema estadounidense -en su mayoría conservadora- han dado inicio a su futura muerte, en especial en materia consumo. En este debate quienes de manera más fuerte han criticado esta herramienta procesal, haciendo un intenso lobby para su reforma e idealmente su supresión, ha sido la derecha republicana y el empresariado. Es por ello que el presente libro ha generado controversia, ya que es un republicano quien ha salido en defensa (moderada, por cierto) de las acciones colectivas.

La obra de Brian Fitzpatrick puede ser leída desde diversas perspectivas. Primero, como un ejemplo patente de lo que se ha denominado el adversarial legalism, es decir, una manifestación de cómo dicho país y su sistema legal se enfrenta a problemas legales contemporáneos desde perspectivas diversas al resto de los países occidentales, enfatizando una cultura de la litigación y adversarialidad $^{1}$.

Otra perspectiva puede ser la política. De hecho, el presente texto no tiene como destinatario a cualquier lector, sino que está escrito por un conservador que, de alguna manera, pretende convencer a gente de su propio sector que lo correcto no es la supresión de este instrumento y que, de hecho, mantenerlo es consistente con sus creencias. Al respecto, el autor afirma que la mirada conservadora siempre ha creído que quien está en la mejor posición para fiscalizar el cumplimiento de la ley (dotado de los mayores incentivos, coherente con una visión de un estado "pequeño" y eficiente fiscalmente hablando) son los abogados privados, por lo que resulta en particular contradictorio que dicho sector sea quien aboga con más fuerza por la supresión de este sistema, el cual, en gran medida, se basa en abogados particulares quienes apuestan por

\footnotetext{
${ }^{1}$ Véase Kagan (2003).
} 
estos casos y asumen su litigación a cambio de un porcentaje de las futuras ganancias. Desde esta perspectiva, el libro es una puerta o ventana a la mente republicana, sus creencias y su visión del Estado y la economía, las que se leen con claridad en los capítulos 2, 3 y 4, donde se explora su filosofía.

Finalmente, este libro puede ser leído como una revisión panorámica de las principales discusiones contemporáneas respecto del sistema de acciones colectivas estadounidense, el cual, sin lugar a duda, ha sido y es un referente mundial $^{2}$. Esta tercera lectura es posible gracias al enfoque que el autor asume y que impacta en la estructura del texto mismo. Dado que este desea defender este mecanismo procesal, diversos capítulos de la obra se hacen cargo de las principales discusiones y críticas que se verifican en la actualidad en dicho país sobre las acciones de clase. Destinaré el resto de la recensión a seguir este enfoque, que me parece es el más interesante para el lector que desea conocer más sobre estas acciones.

En esta línea, es fundamental mencionar el capítulo I, el cual es titulado "La Irónica historia de las acciones colectivas" (The Ironic History of Class actions) ${ }^{3}$. Dicho capítulo es de particular interés primero porque explica los principales pilares conceptuales del régimen de acciones colectivas estadounidenses. También, porque da cuenta del origen de la institución y explica de manera muy clara por qué el fallo de la Corte Suprema Estadounidense en el caso At\&T Mobility vs. Concepción dio pie al inicio al "fin" de las acciones colectivas.

En este capítulo hay dos ideas que resaltan con mucha fuerza. La primera se relaciona con el origen de las acciones de clase. Si bien existía un antecedente histórico, fue el cambio introducido en la década de 1960 a las reglas federales de procedimiento civil las que consagraron el régimen tal como hoy se conoce. En este escenario el texto muestra que la reforma legal no provino del congreso, ni de la sociedad civil, sino que desde el sistema de justicia o, como lo llama Brian Fitzpatrick de un "oscuro comité de abogados, profesores de derecho y jueces"4. Este resalta que todo el proceso de creación de estas reglas se difundió muy poco y por ello no muchas personas tenían información sobre esta reforma legal, lo que no favoreció un mayor debate. En este punto, al lector interesado en los procesos de reforma a la justicia de nuestro país le parecerá inevitable la comparación con los intentos (fallidos, por cierto) de reforma a la justicia civil, los cuales en su gran mayoría se han llevado de la misma manera.

${ }^{2}$ Gidi (2004), pp. 1, 17-19. Asimismo, Deborah Hensler destaca que, incluso, en el desarrollo europeo de sistemas de litigación colectiva el modelo estadounidense ha sido usado como un referente negativo, esto es, para evitar ciertos rasgos y problemas de dicho modelo. Incluso eso explica que en Europa no se hable de acciones colectivas, sino que de mecanismos de reparación colectiva (collective redress). Hensler (2017), p. 968.

${ }^{3}$ La idea de que la historia de las acciones colectivas es "irónica”, según este autor, tiene relación con que al momento en que se propuso este mecanismo, había voces que creían que iba a favorecer a las empresas, lo que con el tiempo no ha sido así en lo más mínimo. FitzPATRIck (2019), pp. 10-11.

${ }^{4}$ Op. cit., p. 9. 
La segunda idea que resalta con fuerza tiene relación con la relevancia, dentro del esquema regulatorio de las acciones colectivas, que tiene la distinción entre opt-in y opt-out. Según Brian Fitzpatrick, el cambio que revolucionó el régimen de acciones colectivas estadounidense fue el paso de opt-in, esto es, que las personas que deseaban ser alcanzadas por el fallo o acuerdo debían solicitarlo, a un régimen de opt-out, donde todos eran alcanzados por el fallo o acuerdo, a menos de que explícitamente dijeran que no lo deseaban ${ }^{5}$. Esta sería, por un lado, la condición que haría a las acciones colectivas tan atractivas para los abogados al permitir la agregación masiva y, por otro, aquella característica que explica muchas otras del régimen, como la necesidad de tener un juez activo que supervise de manera intensa el procedimiento, el comportamiento de los abogados y en especial, la justicia de los acuerdos.

Al respecto, Brian Fitzpatrick explica con mucha claridad, que el problema central de las acciones colectivas son los potenciales escenarios de colusión entre los abogados demandantes y las empresas mismas, lo que justificará el papel del juez en esta materia. Asimismo, más adelante en el texto se indica que esta potencial colusión -y uno podría agregar, permanente situación de potencial conflicto de interés- se ve favorecida por la inevitable mayor lejanía (more divorce from) entre el abogado y sus clientes, dado que muchos de ellos ni siquiera saben que existe una demanda en su nombre ${ }^{6}$.

Otro capítulo en el que es importante detenerse es el tercero, donde el autor presenta las distintas alternativas que se contemplan para asegurar el adecuado cumplimiento de la ley, indicando que estas se ubican entre dos polos, "abogados estatales o abogados particulares"

En este capítulo se detalla de manera sencilla las principales teorías que apoyan la privatización del cumplimiento de la ley que subyace a la visión conservadora sobre la materia. Con independencia de que uno pueda o no compartir dicha visión, el capítulo hace un buen trabajo presentando de manera sintética las distintas razones para ello ("un estado más pequeño", "autonomía", "mejores incentivos", "mejor uso de los recursos" y "menor sesgo político")

Ahora bien, este capítulo debería ser en especial interesante para el lector nacional, en la medida que permite hacer un contraste entre el sistema estadounidense y el chileno, el cual hasta no mucho tiempo atrás giraba completamente en torno al Sernac. La teoría presentada grafica muy bien algunos de los problemas a los que está expuesto el Servicio, como las acusaciones de sesgo político, al depender del Ministerio de Economía de turno.

Los capítulos 6 a 8 son muy relevantes en la obra, ya que en cada uno de ellos Brian Fitzpatrick se hace cargo de las principales críticas/problemas del régimen estadounidense de acciones de clase. $\mathrm{El}$ primero de ellos se titula " $\mathrm{iCa}$ -

\footnotetext{
${ }^{5}$ FitzPatrick (2019), p. 11.

${ }^{6}$ Op. cit., p. 70.

${ }^{7}$ Op. cit., p. 29.

${ }^{8}$ Op. cit., pp. 33-44.
} 
recen de fundamento las demandas colectivas?" (“Are class actions meritless?”), el segundo " ¿Es efectivo que los abogados se quedan con el dinero? ("Do class actions lawyers get all the money?") y " $\mathrm{L}$ Las acciones colectivas desincentivan el mal comportamiento?" ("Do class actions deter wrongdoing?"). Al respecto, es necesario destacar uno de los aspectos que, en mi opinión, son más relevantes e interesantes de este trabajo, y en general de la academia estadounidense, que se refiere al uso de información empírica en conjunto con el análisis legal.

Es así como en cada uno de estos capítulos el autor no solo da cuenta de que conoce las principales discusiones jurídicas en cuanto a este instrumento procesal, sino que sus opiniones están basadas igualmente en estudios empíricos que permiten salir del anecdotismo y las "historias de guerra" que tanto abundan en la academia latinoamericana.

Por ejemplo, en el capítulo 6 referido al mérito "real" de las demandas colectivas, Brian Fitzpatrick explica con mucha claridad que en el sistema estadounidense existe una herramienta procesal a bajo costo que permite impedirlas (llamado motion to dimiss), a través de la cual la jueza, en un momento muy temprano del proceso, puede rechazar la demanda que no tiene plausibilidad real. En este contexto el autor expone diversos estudios que señalan que solo entre un $20 \%$ a $30 \%$ de dichas mociones son acogidas, por lo que la mayoría de las acciones colectivas presentadas tendrían algún mérito ${ }^{9}$.

Luego, se da cuenta de un estudio empírico original que examinó el monto de los acuerdos alcanzados. En el estudio identificó el quantum por el cual tradicionalmente las compañías llegan a acuerdo en estos casos, solo con el fin de hacerlos desaparecer. Los resultados de su investigación mostraron que en la mayoría de los casos los montos acordados superaban dicho umbral, por lo que no solo se habría llegado al acuerdo por razones costo-oportunidad, sino que sugiere que dichos casos tendrían algún mérito adicional para justificar un acuerdo por sumas superiores.

Otro ejemplo se da en el capítulo sobre si los abogados se "quedan" con el dinero (capítulo 7). El autor examina los montos por concepto de quota litis que fueron pagados a los abogados, los cuales en promedio eran de un 25\% del monto recuperado, muy por debajo del $40 \%$ que algunos indicaban. Asimismo, resalta la relevancia de los mecanismos de fluid recovery, en el cual las sumas no distribuidas se derivan a entidades de beneficencia.

Este capítulo es de particular interés por tres razones. Primero, porque muestra la profunda conexión que existe entre el régimen de acciones colectivas estadounidense y el sistema de cobro de los abogados. En esta línea él se da cuenta de que un elemento central de dicho régimen consiste en el sistema de contigency fee, el cual supone que quien asume el riesgo de litigar la acción de clase son en realidad los abogados, dado que estos solo se pagarán en el evento de un fallo favorable o un acuerdo. El autor explica con mucha claridad cómo el sistema estadounidense de acciones colectivas en gran medida se ha

\footnotetext{
${ }^{9}$ FitzPatrick (2019), p. 75.
} 
desarrollado producto de la interacción del cambio hacia un sistema opt-out y esta forma de cobro de honorarios.

Un segundo elemento a que el capítulo se refiere, explica las distintas medidas que los jueces han tomado con el fin de cambiar este sistema de honorarios, tratando de disminuirlos, dando pie al sistema de lodestar, que se basa en las horas de trabajo más que en los resultados obtenidos. En este punto el autor muestra, haciendo uso de ciertos conceptos del análisis económico del derecho, cómo este mecanismo es menos eficiente.

Con todo, lo más relevante del capítulo 7, y que considero es algo fundamental a tomar en cuenta en nuestro país, tiene relación con como medir la eficacia en cuanto a la reparación que proveen las acciones colectivas. Al respecto, el autor distingue que es fundamental en este análisis poner atención respecto de cuánto dinero o beneficios fueron efectivamente distribuidos a los beneficiarios por el acuerdo o el fallo y no quedarse en las sumas "nominales" ${ }^{10}$. En este capítulo el autor reconoce que esta es probablemente una de las críticas más fuertes a este sistema ${ }^{11}$. Este capítulo debería a llevar a reflexionar sobre qué tan efectivas son las reparaciones que se obtienen para los consumidores en Chile en la actualidad y qué tan efectivas son las actuales auditorías que el Sernac exige.

Para finalizar, en el capítulo 9 de la obra Brian Fitzpatrick reconoce que desea mantener este régimen de "cumplimiento privado" de la ley, pero asumiendo su tendencia conservadora propone algunas modificaciones a la legislación actual. Dentro de las que más llama la atención es aquella que afecta la naturaleza transustantiva de las acciones colectivas.

En Estados Unidos el régimen de acciones colectivas es de aplicación general, por lo que cualquier materia, no solo consumidor, sino que laboral o de otra índole, puede ser sometida al conocimiento del tribunal a través de este instrumento. Por eso se dice que es transustantiva. En este punto, Brian Fitzpratick propone mantener este régimen, pero quitarle esta naturaleza y, por tanto, que el Congreso estadounidense decida qué tipos de casos pueden litigarse de esta manera. Frente a esto uno podría preguntarse qué tanto impacto tendría este régimen especial de tramitación si pierde esta característica.

Asimismo, esta propuesta le resultará llamativa al lector nacional, ya que notará que se acerca de alguna manera a la situación de los países del derecho continental, donde lo normal es que estos regímenes procesales solo se autorizan para ciertas materias, típicamente consumo. También debería llamar la atención lo opuesto, es decir, qué otras materias en nuestro país podrían verse mejoradas en cuanto al acceso a la justicia y a la real vigencia del derecho si se estableciera un mecanismo de esta índole. En este escenario se podría pensar en la situación del recurso de protección o los juicios laborales.

\footnotetext{
${ }^{10}$ Más de algún lector recordará la más reciente versión criolla de este problema, el caso del papel tissue y las famosas "7 lucas". Dudas sobre cuánto finalmente recibirían los consumidores se plantearon durante todo el proceso de difusión e implementación.

${ }^{11}$ FitzPatrick (2019), p. 88.
} 
No quisiera dejar de mencionar algunas de las críticas que esta obra merece, en concreto, este trabajo no parece en su análisis darles la suficiente relevancia a dos problemas de las acciones colectivas estadounidenses, ampliamente documentados por la academia de dicho país.

Primero, destaca la obra el importante papel que los jueces tienen en todo el esquema, siendo aquellos llamados a evitar la colusión, los conflictos de interés y el asegurar un mínimo de debido proceso para los miembros "ausentes", muchos de los cuales están siendo representados sin saberlo. El autor parece poner mucha fe en los jueces, cuando es sabido que en este tipo de materias hay un porcentaje de jueces que solo de manera formal cumplen este papel. Parece difícil evaluar el régimen de acciones colectivas sin tener más información sobre el comportamiento real de los jueces.

Segundo, es llamativo que el autor no provea de más información tanto teórica como empírica acerca de los efectos que produce la combinación del sistema de discovery estadounidense y el régimen de acciones colectivas. De alguna manera, aquel lector de esta obra que tiene algo más de conocimiento de este sistema, tiene la percepción de que hay un elefante en la habitación del cual solo se habla de modo tangencial. En este punto, algunas de las defensas que el autor realiza sobre el régimen, como si los acuerdos a los que se llega son meritorios o no, no solo dependen del mérito de la acción misma, sino que de los costos que el proceso de discovery pueden suponer. Esto parece reconocerlo en su último capítulo, cuando proponer modificaciones a este sistema de intercambio de información, pero se echa de menos que carezca de un papel más protagónico.

A pesar de lo anterior, me parece que el aporte de la obra es indiscutible, no solo en la academia estadounidense, sino que, también, para aquellos abogados y académicos interesados en las acciones colectivas y su funcionamiento. La obra en un inglés sencillo y directo es capaz de proveer al lector de una visión panorámica actualizada sobre el estado de esta herramienta procesal, describiendo las principales discusiones y desarrollos. Igualmente, se presta para un ejercicio permanente de contraste con el régimen de acciones colectivas criollo, entregando herramientas conceptuales útiles para conducir a un análisis institucional y de dinámicas de litigio que beneficiará al lector nacional interesado en estas materias.

\section{Bibliografía CITADA}

GIDI, Antonio (2004). Las acciones colectivas y la tutela de los derechos difusos, colectivos individuales en Brasil: Un modelo para países de derecho civil. México: Universidad Nacional Autónoma de México.

Hensler, Deborah (2017). "From Sea to Shinning Sea: How and Why Class actions are spreading globally”. Kansas Law Review, vol. 65. Kansas. 
Kagan, Robert (2003). Adversarial Legalism: The American Way of Law. Cambrigde, Massachusetts: Harvard University Press.

Siglas y ABREviaturas

op. cit. opere citato (obra citada)

p. página

pp. páginas

Sernac Servicio Nacional del Consumidor

vs. versus

Vol. volumen

Claudio Fuentes Maureira ${ }^{12}$

${ }^{12}$ Abogado y Magister en Derecho Penal y Procesal Penal. Universidad Diego Portales. Master of the Science of Law (J.S.M). Profesor de Derecho Procesal e investigador Universidad Diego Portales. 